\title{
Striving for a more sustainable Belgian dwelling stock
}

\author{
K. Allacker ${ }^{1}$, F. De Troyer ${ }^{1}$, C. Spirinckx ${ }^{2}$, L. De Nocker ${ }^{2}$, \\ A. Vercalsteren ${ }^{2}$, B. Tomasetig ${ }^{2}$ \& K. Putzeys ${ }^{3}$ \\ ${ }^{I}$ Department of Architecture, Urbanism and Planning, \\ Faculty of Engineering, K.U. Leuven, Belgium \\ ${ }^{2}$ Flemish Institute for Technological Research, VITO, Belgium \\ ${ }^{3}$ Belgian Building Research Institute, BBRI, Belgium
}

\begin{abstract}
A four-year project (SuFiQuaD) started in 2007 to optimize the Belgian dwelling stock. The optimization focuses on environmental impacts, financial cost and quality aspects. The aim is to evaluate the whole life cycle of representative housing types and formulate recommendations for improvement. In a first phase the methodology has been developed and is now being applied to a limited selection of extreme dwelling types. Based on this application, the methodology will be revised and applied to representative dwelling types. This paper elaborates on the developed methodology and the first results of the implementation. The basic approach for the optimisation is to search for the highest marginal quality improvement for the additional cost. The cost consists of different aspects: initial financial cost, initial environmental cost, life cycle financial cost and life cycle environmental cost. The environmental cost is calculated by translating the environmental impact - estimated based on life cycle assessment - into financial terms. Finally, a quality evaluation is included. This is considered as an essential part of the analysis since a good quality is a requirement for sustainability, but moreover, the inclusion of the evaluation of the performance of a building enables comparative analysis.
\end{abstract}

Keywords: life cycle assessment, life cycle costing, multi-criteria analysis, optimisation, Pareto, dwelling, monetary valuation, marginal valuation, Belgium, element method, quality assessment. 


\section{Introduction}

The Belgian dwelling stock is far from sustainable at the moment. Not only are the houses poorly insulated, but hardly any attention is paid to the environmental impact of the applied building materials. Furthermore a lot of transportation is generated and the amount of building waste is enormous. Although people are more conscious than a decade ago and the government has undertaken some important measures, no overall change is noticeable. This can partly be explained by the relatively long lifespan of buildings leading to a slow renewal/improvement of the existing dwelling stock. However more action is needed and a more integrated approach is required. The research described in this paper is an attempt to search for priority actions.

\section{Integrated approach}

The approach within this research is an integrated approach since the different stakeholders are addressed, the whole life cycle of the dwelling is included and both costs (financial and environmental) and qualities are analysed. In the following paragraphs the different aspects of this integrated approach are briefly described. In a second part of the paper the first results from the implementation to one of the extreme dwelling types are discussed.

\subsection{Environmental impact}

The evaluation of the environmental impact of the dwellings is based on a life cycle assessment (LCA [1-6]). For the inventory of the environmental data of the building related products and processes we rely mainly on the Ecoinvent database [7]. For the assessment of the inventoried in- and outputs; the effects as defined within eco-indicator 99 are considered [8]. However a method has been developed to express the impacts into financial terms instead of ecopoints. This method is based on a combination of existing methods and can therefore be called a hybrid method. For the environmental effects of the greenhouse gas emissions, the monetary value is based on the combined information from Tol [9], Stern [10] and Watkiss et al. [11-12]. The monetary value of other airborne emissions is based on the ExternE studies, more specific the values of the CAFE (Clean Air For Europe) project are used [13]. However a comparison of these emissions with the ones assessed within Eco-indicator 99 revealed that for the building related products and processes ExternE was excluding too many important emissions. Therefore a monetary value was determined for the 'disability adjusted life years' (DALYs) caused by the emissions not included within ExternE. These values were based on different sources and led to the value of 60.000 euro/DALY [14]. Moreover the impact on the quality of ecosystems and the depletion of resources, as assessed by Eco-indicator 99, still needed to be included since these again proved not to be negligible for the building related products and processes analysed. Acidification, eutrophication, ecotoxic emissions and land use are therefore included by translating the (PDF $\mathrm{x}$ 
$\mathrm{m} 2 \times$ year), as assessed within Eco-indicator 99, into monetary values based on the studies mentioned before. The value of 0,49 euro/(PDF $\times$ m $2 \times$ year) was retained. For the depletion of minerals and fossil fuels, the monetary value of 0,0065 euro/MJ surplus energy was determined.

For the analysis of the extreme dwelling type described in this paper, some environmental costs were still lacking: the construction and demolition cost, maintenance costs and the transportation during use phase are omitted.

\subsection{Financial cost}

In this research, we analyse the investment cost, the periodical costs and the costs at the end of the lifespan of the dwelling by calculating the sum of the present values. We refer to the literature for a more detailed description of Life Cycle Costing [15]. Since it is difficult to predict how material, labour and energy costs will evolve in future, a sensitivity analysis is required.

The required data for the material and labour costs are taken from the ASPEN database, valid for the Belgian context [16]. If data were missing, product specific data were used.

For the description of the analysis of the extreme dwelling type in this paper, the financial cost for the demolition and end-of-life treatment are not included yet. As for the environmental cost, the financial cost for maintenance and transportation during use phase are omitted too. Moreover the financial cost of the heating installation is not yet included.

\subsection{Quality evaluation}

Finally, a quality evaluation is included in order to enable comparative analysis of the different dwelling and technical performances. The applied method is based on an existing method, consisting of a multi-criteria analysis [17]. The different quality aspects obtain a score on ten, defined by a score function. The single end-score is calculated by the sum of the weighted scores. Within the original method, the weighting factors were defined by an expert panel.

Some adaptations have been made to the original method. First of all, some aspects have been eliminated to avoid double counting (e.g. the score for financial cost and energy use for thermal insulation are excluded since these are already considered in our cost evaluation). Secondly, some score functions have been redefined according to the new European and Belgian norms (e.g. acoustical standards). Thirdly the weighting factors have been revised based on pair-wise comparison of the aspects. From these results, weighting factors have been determined through an Analytic Hierarchic Process (AHP).

\subsection{Functional unit}

The functional unit is chosen as one square meter of net floor area, per year to enable comparative analysis of dwellings with different size, layout and lifespan. However, to avoid conclusions as "the larger the house, the more sustainable", the results are also calculated per inhabitant, per year. For the analysis of the 
extreme dwelling type presented in this paper, the size of the dwelling is fixed and therefore the results will only be shown per square meter floor area, per year.

The relatively long lifespan of dwellings makes the use phase an important part of the life cycle and is therefore investigated in detail. The lifespan however is hard to predict, and therefore again, a sensitivity analysis is made. The dwellings are assumed to have a lifespan of 60,90 and 120 years. However the results in this paper are only elaborated for the two extremes (60 and 120 years).

\subsection{Optimisation}

For the determination of the most preferable measures for one type of dwelling, or for the determination of the most preferable dwelling type, the basic approach is to search for the highest marginal quality improvement for the additional cost. This means that one starts from a reference building and compares the alternatives with this reference. The subset of options that is more preferable than the other options is graphically represented by the Pareto front.

Different optimisation criteria are considered: initial financial cost, initial environmental cost, life cycle financial cost and life cycle environmental cost, initial total cost and life cycle total cost, with and without the inclusion of the quality evaluation. It is possible that these different criteria will lead to a different ranking of the optimal options.

\section{Simulation tool}

The above summarized method has been translated into a simulation tool. This tool relies on an extended database containing all required data of the work sections occurring in the dwellings. These are structured per element of the dwelling according to the element method for cost control $[15,18,19]$. The database is structured according to the $\mathrm{BB} / \mathrm{SfB}$ code [20].

Each element is constituted of work sections selected from the database, which are multiplied with an appropriate ratio (= quantity of work section per unit of element). The elements are defined in such a way that these are as independent as possible. Replacing one element solution by an alternative (other size, other materials) should not influence the other elements. However, for some elements this was impossible. For example, increasing the thickness of the exterior walls (by adding insulation for example) influences the roof edge, the foundation and the fixing and finishing of windows and doors. Elimination of unrealistic combinations requires additional computation time and should further be optimized.

For each element occurring in the dwelling, a unit ratio (= quantity of element per $\mathrm{m}^{2}$ floor) is calculated. Finally the elements are combined at the building level by multiplying the cost per unit element with the respective ratio. The element table for the extreme dwelling type analyzed in this paper is summarized in figure 1.

The calculation of the energy demand for heating during the use phase is based on Belgian Energy Performance Regulations. Electricity use for the use of electrical appliances and lighting is not included in the analysis. 


\begin{tabular}{|c|c|c|c|c|c|c|c|c|c|c|}
\hline Element & amount & unit & ratio & $\begin{array}{c}\mathrm{IF} / \mathrm{m} 2 \mathrm{f} \\
\text { net }\end{array}$ & $\begin{array}{c}\mathrm{IE} / \mathrm{m} 2 \mathrm{f} \\
\text { net }\end{array}$ & $\begin{array}{c}\mathrm{PF} / \mathrm{m} 2 \mathrm{fl} \\
\text { net }\end{array}$ & $\begin{array}{c}\mathrm{PE} / \mathrm{m} 2 \mathrm{fl} \\
\text { net }\end{array}$ & $\begin{array}{c}\mathrm{EOL} \\
\mathrm{F} / \mathrm{m} 2 \mathrm{fl} \\
\text { net }\end{array}$ & $\begin{array}{c}\text { EOL } \\
\text { transport } \\
\text { E/m2fl net }\end{array}$ & $\begin{array}{c}E O L \\
\text { E/m2fl } \\
\text { net }\end{array}$ \\
\hline$(13 .+)$ ground floor_T1 & 159,00 & $\mathrm{~m} 2$ & 1,000 & 201,29 & 28,90 & 108,06 & 28,98 & 0,00 & 4,61 & $-19,54$ \\
\hline (16.4) foundation & 79,24 & $\mathrm{~m}$ & 0,498 & 27,27 & 10,19 & 0,00 & 0,00 & 0,00 & 2,02 & $-20,22$ \\
\hline$(21 .+)$ external wall T1 & 174,87 & $\mathrm{~m} 2$ & 1,100 & 220,78 & 14,96 & 132,10 & 9,76 & 0,00 & 0,49 & $-4,00$ \\
\hline$(22.1+)$ loa dbe a ring inte rna I wall & 0,00 & $\mathrm{~m} 2$ & 0,000 & 0,00 & 0,00 & 0,00 & 0,00 & 0,00 & 0,00 & 0,00 \\
\hline$(22.3+)$ not-loa dbe a ring inte rna I wall & 105,33 & $\mathrm{~m} 2$ & 0,662 & 65,99 & 2,26 & 252,69 & 8,58 & 0,00 & 0,15 & 1,18 \\
\hline$(27.1+)$ flat roof & 159,00 & $\mathrm{~m} 2$ & 1,000 & 219,17 & 13,43 & 179,76 & 7,32 & 0,00 & 0,90 & $-3,76$ \\
\hline (31.) door exte rnal wall & 2,33 & $\mathrm{~m} 2$ & 0,015 & 0,00 & 0,00 & 0,00 & 0,00 & 0,00 & 0,00 & 0,00 \\
\hline (31.) windows & 35,06 & $\mathrm{~m} 2$ & 0,221 & 86,00 & 15,01 & 0,00 & 0,00 & 0,00 & 0,00 & $-0,61$ \\
\hline$(31 .+)$ wind ow finishes & 35,06 & $\mathrm{~m} 2$ & 0,221 & 4,71 & 0,00 & 0,01 & 0,00 & 0,00 & 0,00 & 0,01 \\
\hline (32.) door internal wa II T1 & 7,46 & $\mathrm{~m} 2$ & 0,047 & 0,00 & 0,00 & 0,00 & 0,00 & 0,00 & 0,00 & 0,00 \\
\hline (37.6) roof edge & 79,24 & $\mathrm{~m}$ & 0,498 & 74,01 & 9,04 & 43,87 & 11,27 & 0,00 & 0,15 & $-1,47$ \\
\hline
\end{tabular}

Figure 1: Simulation tool: element table derived for the freestanding house.

\section{Extreme dwelling types}

As explained before, the method is being implemented at the moment to selected extreme dwelling types in order to validate both the approach and the simulation tool. In the following paragraphs, the results will be discussed for a freestanding newly built dwelling. However the approach is also valid for renovation.

\subsection{Freestanding house: description}

The analysed extreme freestanding house is L-shaped, consists of only a ground floor level and is therefore not compact at all $(\mathrm{C}=0,75 \mathrm{~m})$. The house consists of a living room, kitchen and bathroom, storage room and three bedrooms. There is an entrance and night hall. There is no garage in the house. The garden is surrounding the house and there is a terrace adjacent to the living room.

For the technical solutions of the different elements, again some extremes were selected. For the exterior walls, cavity walls consisting of bricks (both inner and outer layer) are compared with other facade finishes (wood claddings, cement fibre board) and with another structural solution, wood skeleton (inner layer). For the flat roof both a concrete slab and wood construction are considered. For the inner walls, "heavy alternatives" of concrete blocks, sandlime brick and clay bricks are compared with the "light" alternative of wood skeleton. For the elements occurring in the building envelope (exterior wall, roof, ground floor and windows) both non-insulated as well insulated alternatives were selected.

\subsection{Freestanding house: cost optimisation}

In the figures below, the results are shown for the freestanding house. The results for the cost optimisation are shown in figure 2. Horizontally the initial cost is plotted, while vertically the total life cycle cost is shown. Both are expressed per square meter floor area, per year.

The options in the left and right grouping of a same symbol represent respectively a lifespan of 120 and 60 years. The former ones obviously lead to lower investment costs per $\mathrm{m} 2$ floor area per year. The life cycle cost of these per 
$\mathrm{m} 2$ floor area per year, however, is not for all options lower than for the options with a shorter lifespan. In the following paragraphs only the results for the dwelling with a lifespan of 120 years are presented more in detail. It is important to report that the subsets of Pareto-optimal solutions for a lifespan of 60 years and 120 years do not necessarily contain the same technical solutions and the identical solutions do not necessarily have the same priority.

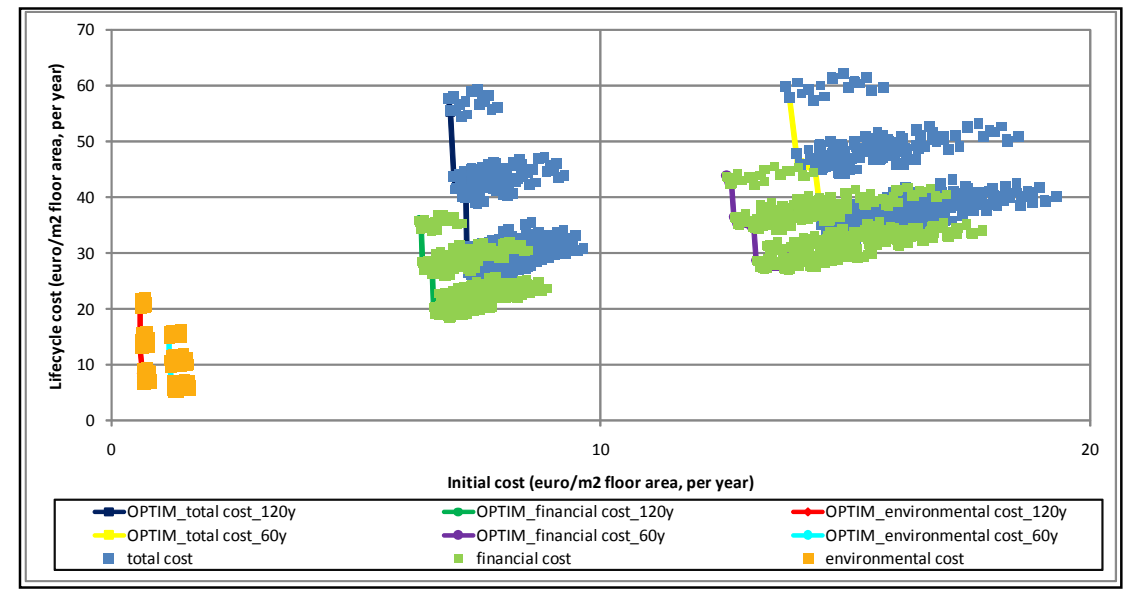

Figure 2: $\quad$ Results optimisation for the freestanding house (60 and $120 \mathrm{y}$ ).

\subsubsection{Financial cost}

The option with the lowest investment cost is called the reference dwelling and proves to be the one which is not insulated, with inner walls of wood skeleton and normal double glazing. Starting from this reference dwelling and for the different options considered, the best investment is to opt for another type of inner walls, namely building bricks. This leads to the highest reduction of financial life cycle cost for the lowest increase of financial investment cost. We must mention that the insulation options considered in this analysis are either no insulation, either a thick insulation layer (two extremes), which can explain the priority of changing an inner wall type above the larger investment of insulating the house.

If a higher investment is possible however, one should preferably invest in ground floor insulation. This requires a higher investment than choosing inner walls of building bricks, but leads to a higher reduction of the life cycle financial cost.

The next investments in order of importance are the following: combination of floor insulation and inner walls of building bricks, roof insulation (wood structure instead of concrete structure), roof and floor insulation, insulated outer walls of wood skeleton instead of building bricks (facing bricks have remained), former one combined with roof insulation, former one combined with floor insulation, and in the final steps changing again to the insulated brick outer wall, 
combined with an insulated roof and floor, inner walls of sand-lime brick with normal double glazing, which is replaced in a final step by thermally improved glazing.

\subsubsection{Environmental cost}

The dwelling with the lowest initial environmental cost is again the not insulated dwelling, but with another type of inner wall, namely the sand-lime brick wall instead of the wood skeleton wall. The measure leading to the highest reduction of life cycle environmental cost for the lowest extra initial environmental cost is achieved by opting for thermally improved glazing instead of normal double glazing. The next measure is insulating the floor but keeping normal double glazing; followed by replacing the glazing again. The fourth step is insulating the exterior walls by choosing for an outer wall of wood skeleton with an outer finishing of wood claddings, combined with normal double glazing, followed by improvement of the glazing. This latter combined with floor insulation, again leads to a lower total environmental cost. A next improvement is insulating the roof, in a first step with normal double glazing, in a next step with improved glazing, followed by insulating the floor, again with normal and improved glazing. In the final step the flat roof is changed from a concrete to a wood structure. The option with the lowest life cycle environmental cost, for the options considered, differs from the one with the lowest life cycle financial cost.

\subsubsection{Total cost}

Finally we can repeat the analysis considering the total cost (sum of financial and environmental cost). The analysis results in an identical reference dwelling and identical final optimal dwelling as for the financial cost analysis. However the steps to evolve from the reference to the final dwelling are more extended now. This indicates that, within a limited budget, the choice based on financial cost considerations will not be identical as the choice based on total cost.

\subsubsection{Detailed analysis of the Pareto optimal solutions}

Figure 3 shows a more detailed analysis of the solutions on the Pareto front as resulted from the optimisation for a dwelling lifespan of 120 years. For each option the importance of the different life phases is shown. This graph clarifies the earlier reported contradiction between financial and environmental optimisation. For, the figure shows that the initial cost is mainly determined by the financial part, while heating the dwelling induces a financial and environmental cost that are more evenly distributed.

\subsection{Freestanding house: cost/quality optimisation}

The graph below shows the results of the optimisation procedure considering the life cycle cost and the quality of the dwelling (figure 4). Again the financial, environmental and total costs are investigated separately. The results in the graph represent the freestanding house with a lifespan of 120 years. The same procedure is used as for the cost optimisation, although now the highest quality increase is searched for the lowest additional cost. As can be seen from the 
figure, the quality is identical for many options. The reason is that the analysed alternatives for technical solutions do not influence the quality to a great extent. For, the chosen technical solutions all fulfil the European and Belgian performance norms and standards. However, the quality evaluation will be more important when optimising the layout of the dwelling and when comparing the different dwelling types.

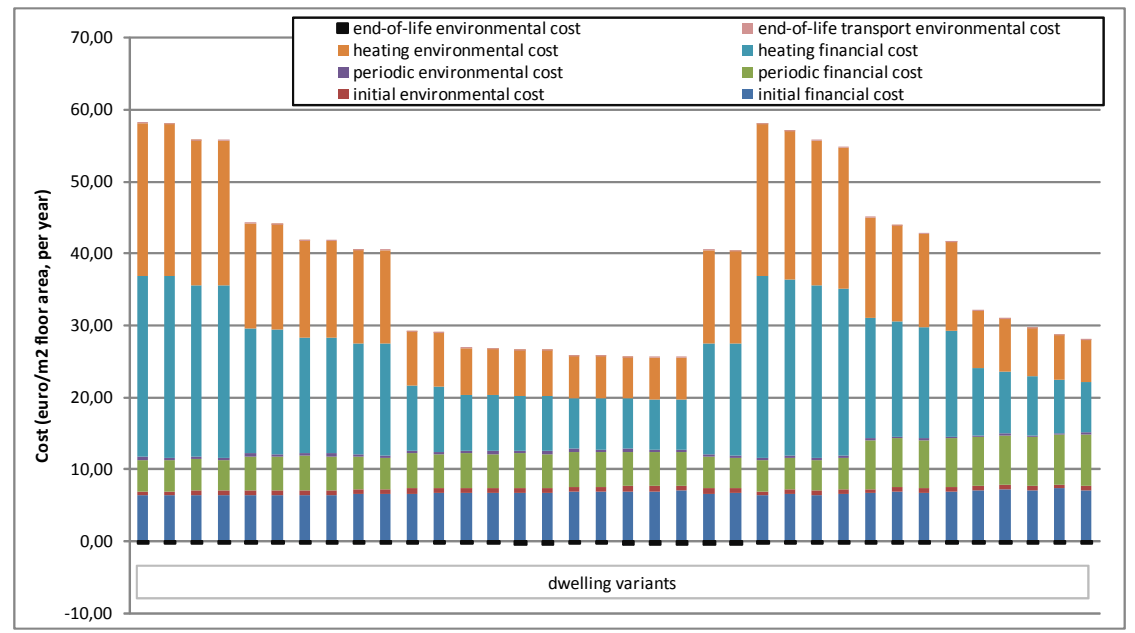

Figure 3: Freestanding house: detailed analysis of the Pareto optimal subset, indicating the importance of the different life phases $(120 \mathrm{y})$.

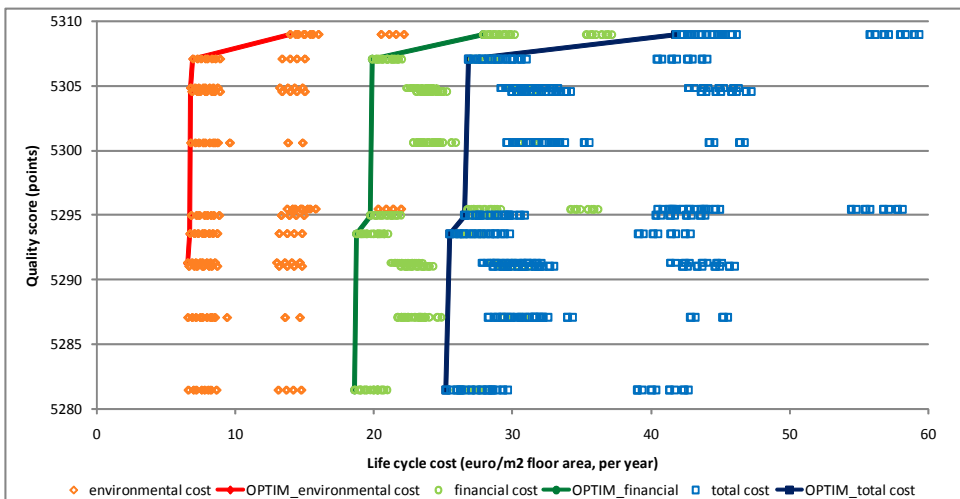

Figure 4: Freestanding house: quality/total cost optimisation, considering life cycle financial, environmental and total cost $(120 \mathrm{y})$.

For the above reason, we will not discuss the above graph in detail. However, it is important to remark that these subsets of Pareto optimal solutions are not identical to the subsets based on the life cycle cost / initial cost Pareto fronts. 


\section{Conclusion and further research}

This paper summarizes the methodology developed within the SuFiQuaD project to optimise the sustainability of the Belgian dwelling stock. Financial and environmental costs are evaluated, including a quality analysis and considering the whole life cycle. Moreover, the translation into a simulation tool and first implementation to an extreme dwelling type have been elaborated. This proved that both the methodology and simulation tool seem valid, although some refinements are still needed. The tool will be implemented to other extreme dwelling types to check compatibility with renovation and multi-family housing (apartments). After refinement, a tool will be available to select priority actions for improvements of different dwelling types and to compare these mutually. Finally it will be used to analyse representative Belgian dwelling types.

\section{Acknowledgement}

Finally, we extend our sincere thanks to BELSPO - SSD (Belgian Science Policy - Science for a Sustainable Development) who funded this research.

\section{References}

[1] ISO 14040, Environmental management - Life cycle assessment Principles and framework, ISO, Paris, 2006.

[2] ISO 14044, Environmental management - Life cycle assessment Requirements and guidelines, ISO, Paris, 2006.

[3] Guinée, J.B. (Ed.), M. Gorrée, R. Heijungs et al., Handbook on Life Cycle Assessment: Operational Guide to the ISO Standards. Kluwer Academic Publishers, Dordrecht, 2002.

[4] a.a., REGENER, European methodology for the evaluation of Environmental impact of buildings - Life Cycle Assessment: application of the life cycle analysis to buildings, Regener project, final report, pp. 145, 1997.

[5] SETAC, Life-Cycle Assessment in Building and Construction: A state-ofthe-art report, SETAC Press, North Carolina, USA, Society of Environmental Toxicology and Chemistry (SETAC), pp. 86, 2003.

[6] SETAC, A technical framework for Life-Cycle Assessment, SETAC Foundation, Pensacola, US, pp. 134, 1991.

[7] http://www.ecoinvent.ch/ (accessed May 2008)

[8] http://www.pre.nl/eco-indicator99/ (accessed May 2008)

[9] Tol Richard S.J., The marginal damage costs of carbon dioxide emissions: an assessment of the uncertainties, energy policy 33, pp. 2064-2074, 2005.

[10] Stern, N., Stern review: The Economics of Climate Change, Cambridge University Press, 2006.

[11] Watkiss P., Downing T.E., Anthoff D. et al., Scoping Uncertainty in the Social Cost of Carbon. Final Project Report, Social Cost of Carbon: A 
Closer look at Uncertainty, Department of Environment, Food and Rural Affairs, London, 2005.

[12] Watkiss et al., The social cost of carbon, review, AEAT, 2005.

[13] Holland M. et al, Damages per tonne emission of PM2.5, NH3, SO2, NOx and VOCs from each EU 25 Member State, document produced in framework CBA of Air Quality related issues, clean air for Europe programme (CAFÉ), AEAT, published by EC, 2005.

[14] De Nocker, L., Liekens I., Vanassche, S., SuFiQuaD - intermediate report, Note on monetary valuation of environmental impacts, BELSPO, pp. 50, 2008.

[15] De Troyer, F., Bouweconomie en Systeembouw, ACCO, Leuven, 2007.

[16] ASPEN index, Nieuwbouw, editie 39, February 2006.

[17] a.a., Ministerie van de Vlaamse Gemeenschap - bestuur Huisvesting, Translated title: Method for the evaluation of the quality of dwellings in the design phase, Methode voor de beoordeling van de kwaliteit van woningen in de ontwerpfase, Belgium, pp. 187, 1991.

[18] a.a., Cost control in building Design, London, Her Majesty's stationery office, 1968.

[19] a.a., Elementenmethode '91, Rijswijk, Stichting Bouwkwaliteit, 1991.

[20] De Troyer, F., Neuckermans, H., Havenne, D., Simon, F., BB/SfB Tabellen 1990, Brussel, Regie der Gebouwen, pp. 135, 1990. 